\title{
Optimisation and characterisation of biosensors based on polyaniline
}

\author{
Kathleen Grennan ${ }^{\mathrm{a}}$, Anthony J. Killard ${ }^{\mathrm{b}}$, Claire J. Hanson ${ }^{\mathrm{c}}$, \\ Attilio A. Cafolla ${ }^{\mathrm{c}}$, Malcolm R. Smyth ${ }^{\mathrm{b}, *}$ \\ ${ }^{a}$ Department of Chemical and Life Sciences, Waterford Institute of Technology, Cork Road, Waterford, Ireland \\ ${ }^{\mathrm{b}}$ National Centre for Sensor Research, School of Chemical Sciences, Dublin City University, Dublin 9, Ireland \\ ${ }^{\mathrm{c}}$ National Centre for Sensor Research, School of Physical Sciences, Dublin City University, Dublin 9, Ireland
}

Received 24 February 2005; received in revised form 26 July 2005; accepted 9 August 2005

Available online 15 September 2005

\begin{abstract}
With lower limits of detection and increased stability constantly being demanded of biosensor devices, characterisation of the constituent layers that make up the sensor has become unavoidable, since this is inextricably linked with its performance. This work describe the optimisation and characterisation of two aspects of sensor performance: a conductive polymer layer (polyaniline) and the immobilised protein layer. The influence of the thickness of polyaniline films deposited electrochemically onto screen-printed electrode surfaces is described in this work in terms of its influence on a variety of amperometric sensor performance characteristics: time to reach steady state, charging current, catalytic current, background current and signal/background ratios. The influence of polymer film thickness on the conductivity and morphology of finished films is also presented.

An electrostatic method of protein immobilisation is used in this work and scanning electron microscopy in conjunction with gold-labelled antibodies and back-scattered electron detection has enabled the direct visualisation of individual groups of proteins on the sensor surface. Such information can provide an insight into the performance of sensors under influence of increasing protein concentrations.
\end{abstract}

Keywords: Characterisation; Biosensor; Polyaniline; Screen-printed electrodes; Scanning electron microscopy; Amperometry; Atomic force microscopy

\section{Introduction}

Conducting polymers have merited applications in recent years in a great variety of fields such as anticorrosive coatings, energy storage systems, gas sensing, as well as electrochromic, electrochemiluminescent and electrocatalytic devices [1]. Over the last decade, these polymers have gained increasing applications in the development of biosensors, especially those incorporating enzymes either as the recognition element (enzymebased biosensors) or as a redox active label (antibody-based biosensors). Enzymes on their own are poor electrochemical communicators, due to the fact that a thick shell of protein insulates their redox centres. Conducting polymers are capable of penetrating this insulating shell and providing a means of direct electrical communication between the redox centre and the electrode surface [2]. They achieve this by delocalising redox

\footnotetext{
* Corresponding author.

E-mail address: malcolm.smyth@dcu.ie (M.R. Smyth).
}

charges over a series of conducting polymer groups, thereby acting as self-contained electron transfer mediators. Consequently, no additional diffusional mediators need be added to the sensing system in order for electron transfer to take place. This phenomenon has been referred to as the "electrical wiring" of the enzyme to the electrode [3]. This has advantages for the longterm stability of the sensor, since the confinement of the mediator to the sensor surface prevents it from leaching into solution, thus eliminating the requirement for a containment membrane. Such moves toward reagentless systems also facilitate the use of such sensors as stand-alone devices.

PANI has gained particular popularity in biosensor applications, partly due to its favourable storage stability and ease of preparation [4]. It is also recognised as the only conducting polymer that is stable in air [5]. PANI can fulfil several important roles in the biosensor including acting as an immobilisation platform for biocomponents and as the electron mediator [6]. The latter role is possible due to the inherent electroactivity of PANI. Conducting polymer films have also been used to confer antifouling properties to the sensor, with the film serving to reject both elec- 
troactive interferents and other fouling species such as proteins [7].

PANI may be deposited onto electrode surfaces through chemical or electrochemical means. Electrochemical polymerisation, through galvanostatic, potentiostatic or potentiodynamic means, offers the potential to incorporate a wider range of dopant ions, since the reaction is carried out in the presence of an appropriate electrolyte rather than a chemical oxidant. Electrochemical oxidation also gives better control over film properties, such as thickness and morphology. For these reasons, this has become the most common method of PANI film preparation for sensor applications and has been the method employed by our group to date in the development of a range of enzyme- and antibody-based biosensors [8-12].

Since PANI films do not retain their conductive character in non-acidic media [13] (i.e. the neutral environments required for most proteins to function optimally), the electropolymerisation process has to be carried out in the presence of a dopant. For this reason, previous work in our laboratory has focused on the development of biosensors incorporating the PANI doped with the poly(vinylsulphonic acid) (PVS) ion [6,8-12]. The inclusion of the latter maintains electrical neutrality in the oxidised form of the polymer and also leads to increases in its structural stability and conductivity at a broader range of $\mathrm{pH}$ values [14].

PANI films were synthesised potentiodynamically in $1 \mathrm{M} \mathrm{HCl}$ by the anodic oxidation of aniline. The polymerisation process was initiated through the formation of resonance-stabilised aniline cation radicals from the protonated aniline monomer. PANI undergoes two redox processes in acidic media, which correspond to two sets of redox peaks observed during the polymerisation process [6]. The thickness of the polymer films deposited increases with successive potential cycles, since increases in both the anodic and cathodic currents, which are associated with the oxidation and reduction of electrode bound polymer, are observed. This method of polymer deposition has the advantage that the amount of electroactive material deposited can be controlled by controlling the number of potential cycles passed. Polymer thickness invariably affects various aspects of resulting sensor performances and these will be discussed in this work.

Sensor behaviour is also known to be strongly influenced by the surface geometry and morphology of the immobilised biolayer [15]. A common approach for the electrochemical deposition of protein onto sensor surfaces is the electrostatic attachment of protein to a previously electropolymerised polymer film on the electrode surface. $\mathrm{Mu}$ and co-workers have produced a series of sensors in this way, to immobilise a variety of enzymes, including galactose oxidase [16], HRP [17], glucose oxidase (GOD) [18], sarcosine oxidase [19], cholesterol oxidase [20] and ascorbate oxidase [21] to a PANI backbone. The PANI fibril has a diameter of approximately $2000 \AA$, which facilitated easy intercalation of these enzymes, whose diameters were in the 52-1000 ̊ range, into the films [16].

Previous work in our laboratory has focused on a similar electrostatic approach for the immobilisation of protein onto PANI/PVS-coated electrodes [6]. In this work, it was assumed that the modification of the electrode surface with antibody was best achieved by using a high protein concentration $(1 \mathrm{mg} / \mathrm{ml})$, so as to maximise the mass of protein on the electrode surface, as is the case with traditional ELISA procedures [6]. The optimal protein binding capacity of the electrode surface was subsequently investigated by modifying PANI/PVS-coated electrodes with a range of concentrations of $\mathrm{HRP}$ and the results have been published previously [10]. This immediately illustrated that, far from being optimal, the $1 \mathrm{mg} / \mathrm{ml}$ protein concentration yielded much lower catalytic signals than lower concentrations of enzyme. The optimum concentration was found to be approximately $0.6 \mathrm{mg} / \mathrm{ml}$. However, very good signals could still be obtained at concentrations far below this. Signals at $0.01 \mathrm{mg} / \mathrm{ml}$ were comparable to $1 \mathrm{mg} / \mathrm{ml}$ in this regard. The same result was obtained when anti-biotin antibody was attached to the polymer backbone and visualised via interaction with biotin-HRP, demonstrating that essentially the mass of protein being bound to the surface was similar irrespective of the nature of the protein being used. It may also be the case that electron transfer at the electrode surface was more efficient at lower antibody concentrations. At higher protein concentrations, steric hindrance due to overcrowding of protein may have blocked the access of substrate to enzymes located closer to the electrode surface. Alternatively, with enzymes located on the outer layers, catalytic events may have occurred before diffusion of charge transfer to the electrode surface could take place. Both of these factors could have contributed to decreased catalytic signals.

A direct visualisation of immobilised protein of varying concentrations on the sensor surface had never been investigated. Such work would explain the amperometric observations described above and would give an increased understanding of the protein binding capacity of sensor surface. This work is also described here.

\section{Experimental}

\subsection{Materials}

Horseradish peroxidase was $200 \mathrm{U} / \mathrm{mg}$ (Sigma P6782) and was purchased from Sigma-Aldrich (Poole, Dorset, UK) as was poly(vinylsulphonic acid) sodium salt (27,842-4). Aniline was purchased from Aldrich (13,293-4), vacuum distilled and stored frozen under nitrogen. The silver enhancer kit (SE100) was also purchased from Aldrich and comprised a silver salt (Solution A), an initiator (Solution B) and a fixer (sodium thiosulphate pentahydrate). $30 \%(\mathrm{v} / \mathrm{v})$ hydrogen peroxide solution $(108,597)$ was purchased from Merck (Darmstadt, Germany). Human chorionic gonadotropin (HCG)- $\beta$ monoclonal antibody-colloidal gold particle (62-H25) was obtained from Fitzgerald Industries Int. (MA, USA).

Carbon paste (C10903D14) was obtained from Gwent Electronic Materials Ltd. (Gwent, UK). Silver conductive ink (Electrodag ${ }^{\circledR}$ PF-410) and dielectric polymer ink (Electrodag ${ }^{\circledR}$ 452 SS BLUE) were purchased from Acheson. Poly(ethylene) terephthalate substrates were Melinex ${ }^{\circledR}$ (pre-shrunk) films obtained from HiFi Industrial Film Ltd. (Dublin 6, Ireland). Seriwash universal screen wash (ZT639) was purchased from Sericol Ltd. (Kent, UK). The silver/silver chloride $(\mathrm{Ag} / \mathrm{AgCl})$ reference electrode was purchased from Bioanalytical Systems 
Ltd. (Cheshire, UK). The platinum mesh $(29,809-3)$ was purchased from Aldrich.

\subsection{Buffers and solutions}

PBS is $0.1 \mathrm{M}$ phosphate buffer, $0.137 \mathrm{M} \mathrm{NaCl}$ and $2.7 \mathrm{mM}$ $\mathrm{KCl}, \mathrm{pH}$ 6.8. This was prepared by mixing solutions containing $0.1 \mathrm{M} \mathrm{Na}_{2} \mathrm{HPO}_{4}, 0.137 \mathrm{M} \mathrm{NaCl}$ and $2.7 \mathrm{mM} \mathrm{KCl}$ and $0.1 \mathrm{M}$ $\mathrm{KH}_{2} \mathrm{PO}_{4}, 0.137 \mathrm{M} \mathrm{NaCl}$ and $2.7 \mathrm{mM} \mathrm{KCl}$ to a $\mathrm{pH}$ of 6.8 .

\subsection{Instrumentation}

Screen-printing was performed with a semi-automated DEK Albany 247 printing machine (Weymouth, UK). A nylon screen (Miller Group Ltd., Dublin 12, Ireland) with a mesh thickness of $77 \mathrm{~T}$ (filaments per centimetre on thick grade thread (35-40\% open area)) and mounted at $45^{\circ}$ to the print stroke was employed. A single square blade rubber squeegee was employed. Carbon and silver layers were cured in a conventional laboratory oven. The ultra-violet (UV) lamp curing system was obtained from UV Process Supply, Inc. (Cortland, Chicago, IL, USA).

All voltammetric and amperometric electrochemical measurements were performed using a BAS100/W electrochemical analyser with BAS100/W software, operating either cyclic voltammetry or time-based amperometric modes. $\mathrm{An} \mathrm{Ag} / \mathrm{AgCl}$ reference electrode and a platinum mesh auxiliary electrode were employed for bulk electrochemical experiments.

Scanning electron microscopy (SEM) was performed with a Hitachi S $3000 \mathrm{~N}$ scanning electron microscope. Images were obtained using either the secondary electron (SE) or backscattered electron (BSE) detection modes. Acceleration voltages of 20 and $10 \mathrm{keV}$ were employed. Atomic force microscopy (AFM) measurements were performed at room temperature and humidity using a Digital Instruments Dimension ${ }^{\mathrm{TM}} 3100$ NanoScope ${ }^{\circledR}$. Profilometry measurements were carried out with a Dektak V 220-Si Stylus Profiler system (Veeco Instruments Ltd., Cambridge, UK). Resistance measurements were carried out using the two-probe technique and a HP 34401A Multimeter (Hewlett Packard, Leixlip, Co., Kildare, Ireland).

\subsection{Production of screen-printed electrodes}

Screen-printed electrodes (SPE) were designed and produced as described previously [9]. Electrodes were cut from the printed sheet leaving excess substrate on either side to a width of $14 \mathrm{~mm}$. Electrodes were then pre-treated in $0.2 \mathrm{M} \mathrm{H}_{2} \mathrm{SO}_{4}$ solution as described previously [11].

\subsection{Polymerisation of aniline on electrode surfaces}

A mixture of $7.8 \mathrm{ml} 1 \mathrm{M} \mathrm{HCl}, 186 \mu \mathrm{l}$ aniline and $2 \mathrm{ml} \mathrm{PVS}$, was prepared and degassed for $10 \mathrm{~min}$. An argon or nitrogen atmosphere was maintained over the surface of the solution throughout. Aniline was polymerised on the surface of the working electrode using voltammetric cycles between -500 and $1100 \mathrm{mV}$ versus $\mathrm{Ag} / \mathrm{AgCl}$ at $100 \mathrm{mV} / \mathrm{s}$ and a sensitivity of $1 \times 10^{-3} \mathrm{~V} / \mathrm{A}$, until the first oxidation peak (representing the leucoemeraldine (LM) radical cation $\left(\mathrm{LM}^{\bullet+}\right)$ ) reached an anodic current value of $-2.8 \mathrm{~mA}$.

\subsection{Immobilisation of protein on electrode surfaces}

Following deposition of PANI/PVS onto the electrode surface, the electrode was transferred to a $2 \mathrm{ml}$ batch cell as previously described [10]. The surface of the polymer was reduced in $2 \mathrm{ml}$ of PBS (degassed for 10 min under nitrogen or argon) at $-500 \mathrm{mV}$ versus $\mathrm{Ag} / \mathrm{AgCl}$ using a sample interval of $500 \mathrm{~ms}$, over $1500 \mathrm{~s}$ and at a sensitivity of $1 \times 10^{-4} \mathrm{~V} / \mathrm{A}$.

Enzyme or antibody was prepared in PBS prior to use. Very quickly after reduction was complete, PBS was removed from the cell and quickly replaced with the protein solution, not under stirring or degassing. Again quickly, oxidation was performed at $700 \mathrm{mV}$ versus $\mathrm{Ag} / \mathrm{AgCl}$ for $1500 \mathrm{~s}$. During this oxidation, the protein became electrostatically attached to the polymer surface. After oxidation was complete, the protein solution was carefully recovered from the cell and re-stored for later use.

\subsection{Amperometry}

HRP at a concentration of $0.5 \mathrm{mg} / \mathrm{ml}$ was immobilised onto the working electrode, according to Section 2.6, which was then incorporated into a batch cell set-up. $\mathrm{H}_{2} \mathrm{O}_{2}$ at a concentration of $8 \mathrm{mM}$ was added to the cell containing $2 \mathrm{ml}$ PBS following the reaching of a steady state at $-100 \mathrm{mV}$ versus $\mathrm{Ag} / \mathrm{AgCl}$, with a sample interval of $500 \mathrm{~ms}$ and sensitivity of $1 \times 10^{-4} \mathrm{~V} / \mathrm{A}$.

\subsection{Resistance measurements}

Measures of the base resistance of electrodes coated with polymer films were performed with a two-point probe and a digital voltmeter. Measurements were made from the edge of the silver conducting track to the centre-point of the sensing surface.

\section{Results and discussion}

\subsection{Influence of polymer film thickness on amperometric responses}

The sensitivity and limit of detection attainable by an analytical sensor inevitably depend on the background current exhibited by the material. For sensors based on polymers, this current is a function of the morphology of the polymer, which in turn will depend on the polymerisation conditions employed and on the nature of the dopant counter ions incorporated into the growing polymer chains [22]. The thickness of the polymer film also dictates the response time of the biosensor as well as the rate of electron transfer. For electrochemically polymerised films, the amount of polymer deposited is directly related to the total amount of charge passed during growth. Although some charge is lost forming oligomers, film thickness can be carefully controlled by growing films to a desired charge value. In the present work, PANI/PVS films of varying thicknesses were grown on electrode surfaces by controlling the number of potential scans 
used in the voltammetric process until a desired charge value, denoted by the current of the first oxidation peak for the $\mathrm{LM}^{\bullet+}$ radical cation, was reached.

Investigations into the optimum thickness of polymer were carried out using the PANI/PVS electrodes in a HRP biosensor format. HRP at a concentration of $0.5 \mathrm{mg} / \mathrm{ml}$ was immobilised onto electrodes prepared with differing thicknesses of PANI/PVS, according to Section 2.6. Previous work on PANIbased amperometric sensors using this method employed 10 redox cycles as standard during the polymerisation process [6]. Depending, amongst other things, on the nature of the underlying electrode in question, this resulted in the deposition of films of varying thicknesses on electrode surfaces. In this work, monitoring of film thickness and hence of sensor properties was achieved by monitoring the current passed during the polymerisation process rather than the number of voltammetric cycles employed to polymerise the monomer. Two sets of redox peaks were noted for the polymerisation of aniline in acidic solution and results were expressed in terms of the anodic current of the first oxidation peak, which corresponded to the formation of the $\mathrm{LM}^{\bullet+}$. The effects that variations in polymer thickness had on the resulting amperometric responses were investigated in terms of time taken to reach steady state, background currents, charging currents and the magnitude of the sensor responses. These were investigated using glassy carbon electrodes (GCEs) as well as SPEs constructed from carbon paste, which have been characterised previously [9].

The influence of polymer film thickness on the time to reach steady state (when a potential of $-100 \mathrm{mV}$ was applied) and hence the response time of the sensor, is illustrated in Fig. 1(A). A pseudo-linear trend was present for both GCEs and SPEs, with the time taken to reach steady state increasing with increasing polymer thickness in both cases. This was as expected since thicker polymer films would require longer discharge periods before substrates or analytes could be introduced. For each thickness, SPE-based sensors took longer to discharge than GCEbased sensors. From these results, it could be concluded that thinner polymer films would therefore be preferable for sensor production, since lower response times would enable analyte to be introduced into the system sooner and shorter analysis times would be a feature of such sensors.

The sensitivity and limit of detection of a polymer-based biosensor has been said to be mainly dependent on the background current exhibited by the polymer [22]. If the background current of a sensor based on these PANI/PVS films is too large, then the contribution from the reduction of $\mathrm{H}_{2} \mathrm{O}_{2}$ by HRP will be difficult to measure [23]. The effect that increasing polymer thickness had on the background charging currents of electrodes is illustrated in Fig. 1(B). A linear relationship (the most linear in terms of $r^{2}$-values for any of the parameters investigated), existed between background currents and the thickness of polymer films. High background currents could limit the contribution from the enzyme catalytic reaction, thereby decreasing the sensitivity of the sensor. Therefore, thinner polymer films would be preferable, especially where lower levels of analyte are to be detected [23].
The initial charging current peak in time-based amperometric experiments was due to the charging of the polymer as a result of its oxidation for $25 \mathrm{~min}$ prior to steady-state experiments and is typical of the behaviour of previous polymer-modified SPEs [6]. The presence of such charging peaks was generally indicative of good sensor performances, since sensors that did not display such charging profiles did not subsequently produce favourable catalytic responses. The effect of polymer film thickness on the magnitude of the charging current is illustrated in Fig. 1(C). Charging currents for both GCE- and SPE-based sensors increased in a pseudo-linear fashion with increasing polymer thickness, although currents for SPE sensors were consistently greater in magnitude than GCE sensors. This can be attributed to the morphology of PANI/PVS films on the underlying electrodes, since polymer films were observed to have slightly different morphologies on GCEs and SPEs (results not shown).

Decreases in experimental time with decreasing polymer thickness were at the expense of lower catalytic current responses for the sensor, as shown in Fig. 1(D). Whereas all other aspects of the amperometric process were found to increase with increasing polymer thickness, steady-state currents were found to initially increase with film thickness, but to decrease for thicker films. In the case of SPEs, this decline began after films were grown to thicknesses where the $\mathrm{LM}^{\bullet+}$ peak current exceeded ca. $-6.3 \mathrm{~mA}$. The decline began sooner for the GCE, with current decreases observed for films grown to thicknesses where the $\mathrm{LM}^{\bullet+}$ peak current exceeded ca. $-4.1 \mathrm{~mA}$. These decreases in sensor response at increased film thicknesses could be attributed to the increased levels of surface cracking observed for such PANI films, as exhibited by SEM analysis of these films (Section 3.3).

A combination of the data plotted in Fig. 1(B and D) resulted in the signal/background (s/b) ratios for GCE and SPE sensors, as shown in Fig. 1(E). Two different profiles were obtained. With regard to sensors based on GCEs, $\mathrm{s} / \mathrm{b}$ ratios decreased exponentially with increasing polymer thickness. This would illustrate that thinner layers of polymer films would be optimal in order to obtain the maximum obtainable outputs for such sensors. However, this exponential decay in $\mathrm{s} / \mathrm{b}$ signals was not evident with regard to sensors based on SPEs. The maximum obtainable output was for sensors based on polymer film thicknesses of ca. $-2.8 \mathrm{~mA}$ peak current. These sensors yielded $\mathrm{s} / \mathrm{b}$ ratios of 24 . Taking this and all the above parameters into consideration, it was therefore decided to maintain the surface coverage to an anodic peak current of $-2.8 \mathrm{~mA}$ for the $\mathrm{LM}^{\bullet+}$ radical cation (approximately 10 redox polymerisation cycles) for subsequent sensor preparations. The thickness of the corresponding polymer films resulted in the optimal amperometric outputs, with fewer contributions from background currents and lower sensor response times in comparison to those generated from other films.

Stylus profilometry is commonly employed for the measurement of surface roughness and step height patterns. In the present work, the technique was employed to determine the actual thickness of polymer films grown until the $\mathrm{LM}^{\bullet+}$ radical cation reached the optimised value of $-2.8 \mathrm{~mA}$. The mean thickness 


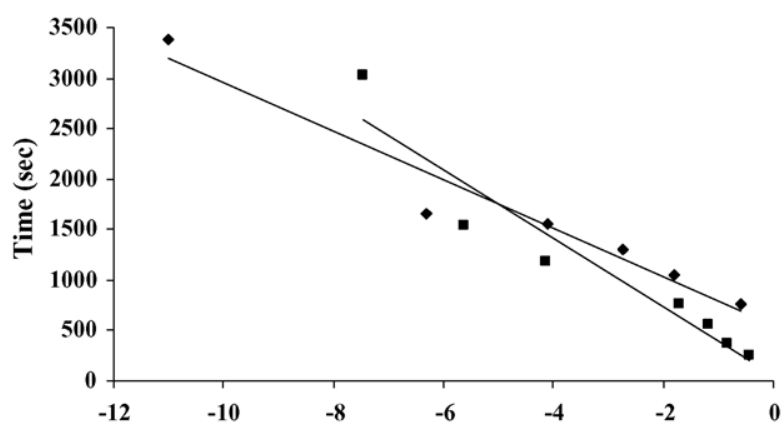

(A)

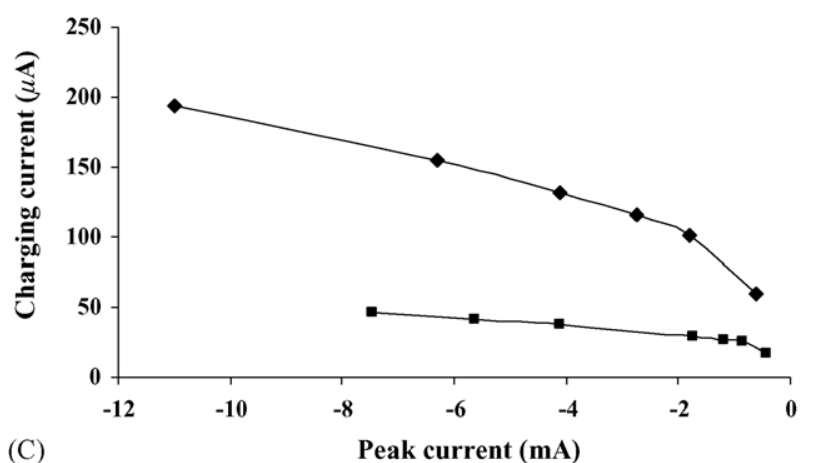

(C)

Peak current $(\mathbf{m A})$

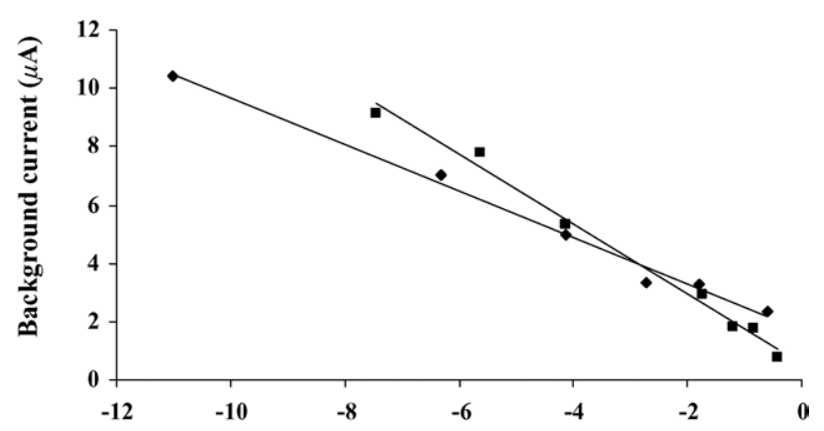

(B)

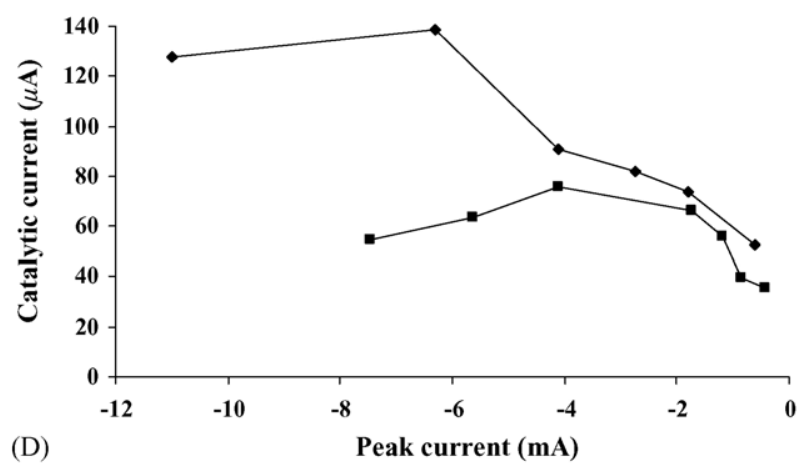

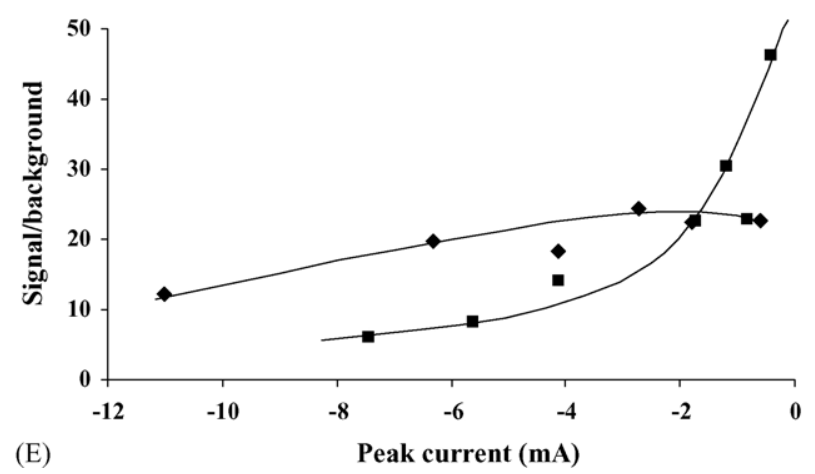

Fig. 1. Effect of polymer thickness on the: (A) response time of sensors based on SPEs, $y=-239.67 x+556.11, r^{2}=0.9489$, and GCEs, $y=-338.96 x+61.379$, $r^{2}=0.9156$; (B) background current responses of sensors based on SPEs, $y=-0.9002 x+1.6848, r^{2}=0.9917$, and GCEs, $y=-1.1924 x+0.5692, r^{2}=0.9899$; (C) charging currents of sensors based on SPEs and GCEs; (D) catalytic currents of the sensor for sensors based on SPEs and GCEs; (E) signal/background ratios for sensors based on SPEs and GCEs (SPE: diamonds, GCE: squares; $-100 \mathrm{mV}$ vs. $\mathrm{Ag} / \mathrm{AgCl}$ ).

of the polymer layer was determined to be $13.7 \mu \mathrm{m}$, with a $R_{\mathrm{a}}$ value of around $3.1 \mu \mathrm{m}$.

\subsection{Influence of polymer film thickness on film resistance}

The resistance and conversely the conductivity of the sensor produced were also found to be dependent on the thickness of polymer films deposited. Using the two-probe technique, the track resistance of a bare carbon SPE was measured to be $2.0 \Omega$ and that of an electrode electrochemically pre-treated as per Section 2.4 to be $3.2 \Omega$. However, with the deposition of PANI/PVS films on these electrodes, sensor resistances increased from the Ohm to the kilo-Ohm range, as illustrated in Table 1. The resistance of the electrodes was found to increase exponentially with increasing polymer thickness, from $0.008 \mathrm{k} \Omega$ at an electrode prepared with 2 voltammetric cycles $(-0.66 \mathrm{~mA})$ to $42 \mathrm{k} \Omega$ for an electrode prepared with 15 voltammetric cycles $(-11.00 \mathrm{~mA})$. Such decreases in conductivity with increasing film thickness

Table 1

Relationship between film thickness and resistance for electrochemically polymerised polyaniline films

\begin{tabular}{lc}
\hline Peak current $\mathrm{LM}^{\bullet+}(\mathrm{mA})$ & Resistance $(\mathrm{k} \Omega)$ \\
\hline-0.66 & 0.008 \\
-2.63 & 0.152 \\
-5.16 & 1.200 \\
-8.53 & 16.200 \\
-11.00 & 42.000 \\
\hline
\end{tabular}


(A)

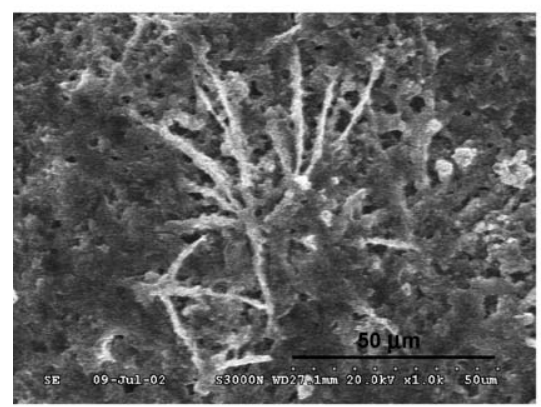

(C)

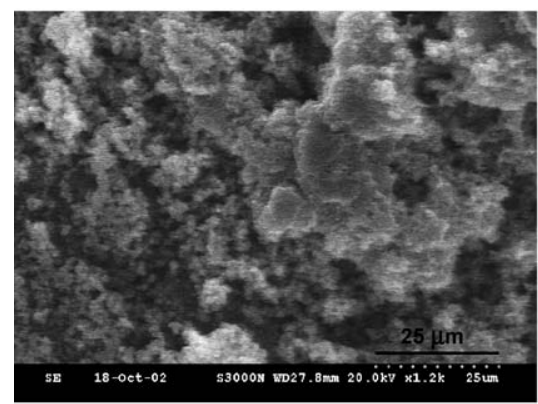

(E)

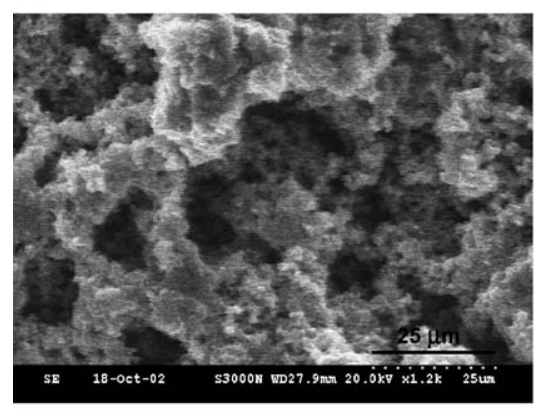

(B)

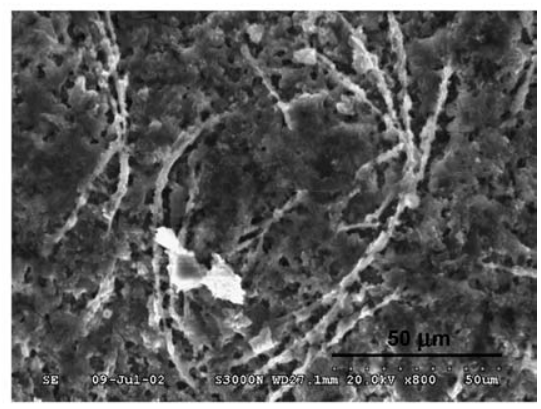

(D)

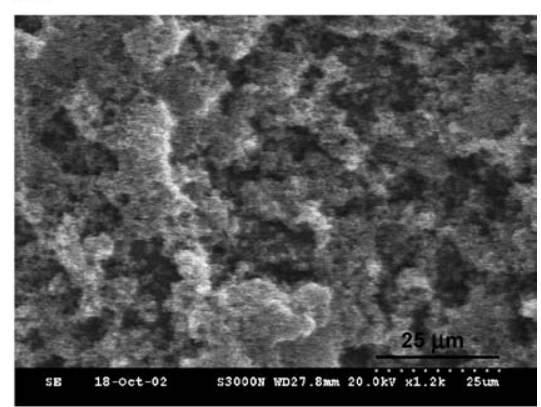

(F)

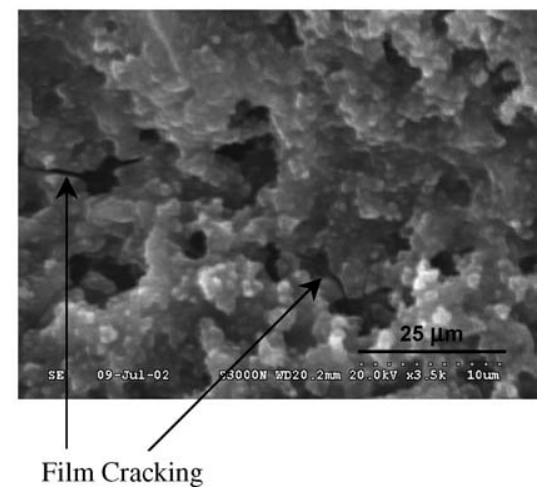

Fig. 2. SEM images of PANI/PVS-coated electrodes at three: (A) 4, (B) 6, (C), 8 (D), 10 (E) and 12 (F) voltammetric cycles $(800 \times, 1000 \times, 1200 \times$ and $3500 \times$ magnifications, SE detection mode).

have been reported elsewhere for polypyrrole films, where the phenomenon was attributed to lengthening of conducting crosslinks between polymer chains [24]. Decreases in conductivity of polypyrrole due to overoxidation have been reported previously [25] and such conductivity decreases have also been reported for increasing thickness of polypyrrole films [26]. In the case of the PANI/PVS electrodes in this work, more pronounced increases in resistance were observed at greater film thicknesses, which could account for the decreases in amperometric responses from sensors produced using such electrodes. Distances from enzyme active sites to electrode surfaces may be too large for effective current transfer on such films, or enzyme-substrate interactions may have taken place before the current had the opportunity to interact with the electrode surface.

\subsection{Influence of polymer film thickness on film morphology}

From a structural point of view, the effects of increasing the number of electrode deposition cycles - and hence the increasing thickness of the PANI/PVS films - can be seen in the typical SEM images shown in Fig. 2. For films grown using three or four cyclic voltammetric cycles, shown in Fig. 2(A and B), 'fingers' of polymer were observed. At six or more voltammetric cycles, as shown in Fig. 2(C-F), these features were no longer evident and buds or nuclei of polymer, dominated the surface of the electrode, giving the polymer a 'cauliflower-like' appearance. At voltammetric cycles greater than 4 but less than 10 , no obvious differences in the structural morphology of the polymer films were observed.

However, films grown using 15 or more voltammetric cycles, began to exhibit cracking, which was evident from SEM images such as that shown in Fig. 2(F). Such cracking could deleteriously affect sensor responses, since this could lead to interruptions in the conducting network and hence reduce electron flow. The decreases in catalytic current outputs observed for such electrodes, outlined previously, could therefore have been due to such surface cracking. However, the thickness of the PANI/PVS film did not affect its adhesion to the underlying electrode 
(A)

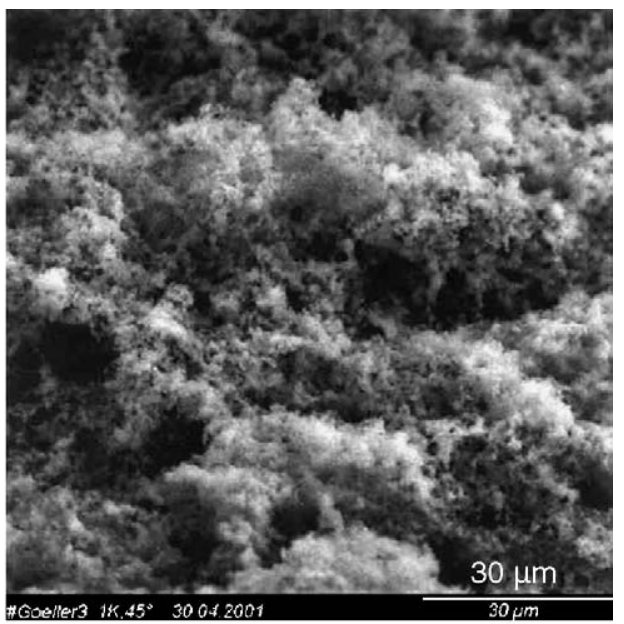

(B)

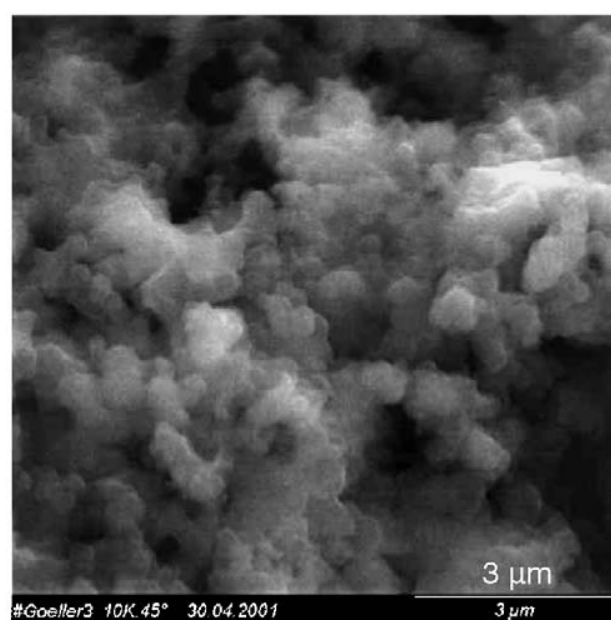

Fig. 3. SEM images of PANI/PVS electrodes electrostatically coated with $0.56 \mathrm{mg} / \mathrm{ml}$ HRP at: (A) $30 \mu \mathrm{m}$ and (B) $3 \mu \mathrm{m}$ resolution $(1000 \times$ and $10,000 \times$ magnifications, SE detection mode).

substrate, unlike the poly ( $N$-methylpyrrole) films developed by Bartlett et al., where thicker films tended to peel from the gold electrode substrate [27].

\subsection{Structural characteristics of proteins absorbed to polymer films}

As explained previously, the optimum concentration of protein immobilised to PANI/PVS-coated electrode surfaces that led to optimal amperometric outputs was found to be approximately $0.6 \mathrm{mg} / \mathrm{ml}$. SEM images of a polymer electrode surface modified with $0.6 \mathrm{mg} / \mathrm{ml} \mathrm{HRP}$ are shown in Fig. 3. In comparison to PANI/PVS images shown in Fig. 2, a light wispy layer of protein had become deposited on the polymer nodes, although the overall 'cauliflower-like' appearance was still prevalent, with proteins immobilised with random orientations to these nodes. At higher magnifications, shown in Fig. 3(B), it was difficult to distinguish these surfaces from those of the PANI/PVS layers shown in Fig. 2. Although SEM is capable of imaging structures down to nanometre dimensions, more powerful imaging techniques were required if clearly resolved images of proteins were to be obtained. Attempts were made to image HRP immo-
(A)

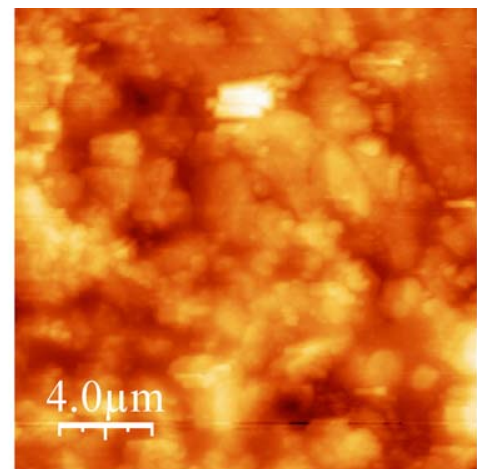

$1.29 \mu \mathrm{m}$

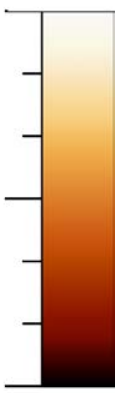

(B)

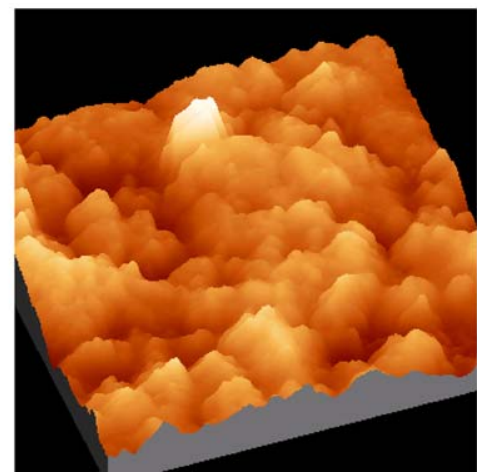

$0.00 \AA$

Fig. 4. 2D (A) and 3D (B) AFM images of a PANI/PVS electrode coated with $0.6 \mathrm{mg} / \mathrm{ml} \mathrm{HRP}$ (tapping mode).

bilised on PANI/PVS-coated SPEs using AFM, with typical images shown in Fig. 4. The nucleation morphology of proteins observed from SEM images was also evident here. What was also apparent was that the protein layer was not evenly distributed over the sensor surface; rather clumping of proteins was evident. The rough nature of the underlying SPE surface meant that the silicon nitride AFM tips were easily broken when brought into contact with the sensor surface. For this reason, further AFM analysis of the protein layers was abandoned and a method for the indirect visualisation of proteins sought.

Although AFM and SEM in the SE detection mode could provide adequate surface information as to the overall topography of protein films, the resolution of individual protein or groups of proteins was not possible. However, through the use of proteins conjugated to a non-fading, electron-dense particle such as gold, it was possible to indirectly visualise the distribution of proteins using the BSE detection technique, which is sensitive to the detection of higher molecular weight particles such as gold and silver. A combination of these techniques provided both high-resolution images (SE), while materially dependent signals (BSE) provided an accurate localisation of Abs on the surface of the electrode, by distinguishing between the underlying PANI/PVS backbone and the protein layer. In some cases, BSE signals can be improved using a silver enhancement step. This process caused the reduction of silver ions, resulting in the precipitation of metallic silver around the colloidal gold particles. Berney et al. have characterised the surface of their chip-based transferrin biosensor using such an enhancement step [15]. In the present work, HCG- $\beta$ monoclonal antibodies conju- 
gated to $15 \mu \mathrm{m}$ colloidal gold particles were employed to image the topography of Ab layers on PANI/PVS-coated SPEs.

BSE and SE images were obtained for surfaces coated with varying concentrations of $\mathrm{Ab}$ from 10 to $0.08 \mathrm{mg} / \mathrm{ml}$ and typical images are shown in Fig. 5. In all SE images, distinctions between the silver-coated gold particles and the polymer surface were not possible. However, with BSE detection, silver-coated gold labels were clearly visible as brighter particles against the darker polymer background. At higher concentrations of antibody-gold colloids, distribution of protein seemed to reflect the height profiles of the underlying polymer, whose profiles can be seen from the SE images. However, at $10 \mathrm{mg} / \mathrm{ml}$ (Fig. 5(A)),

\section{SE images}

(A)

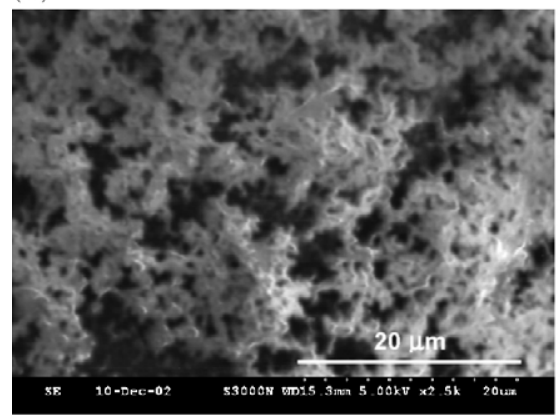

(B)

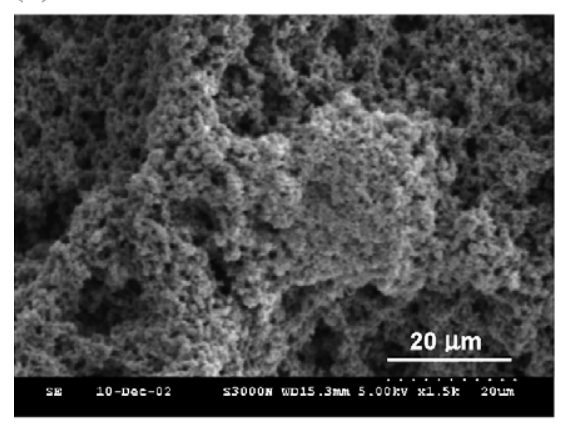

(C)

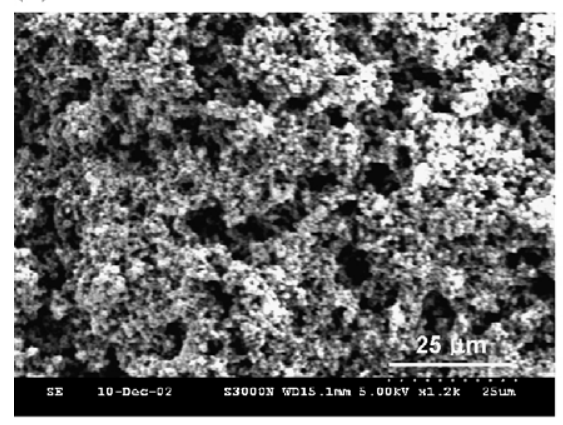

(D)

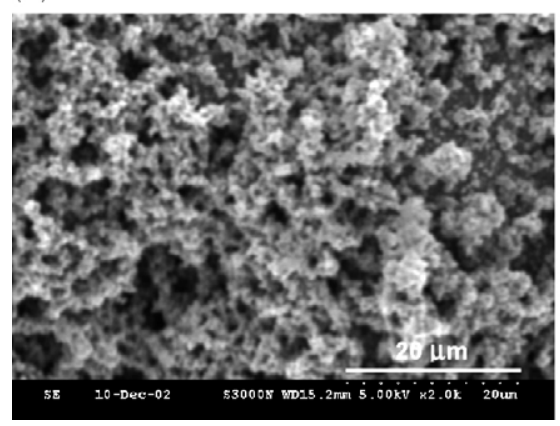

BSE images
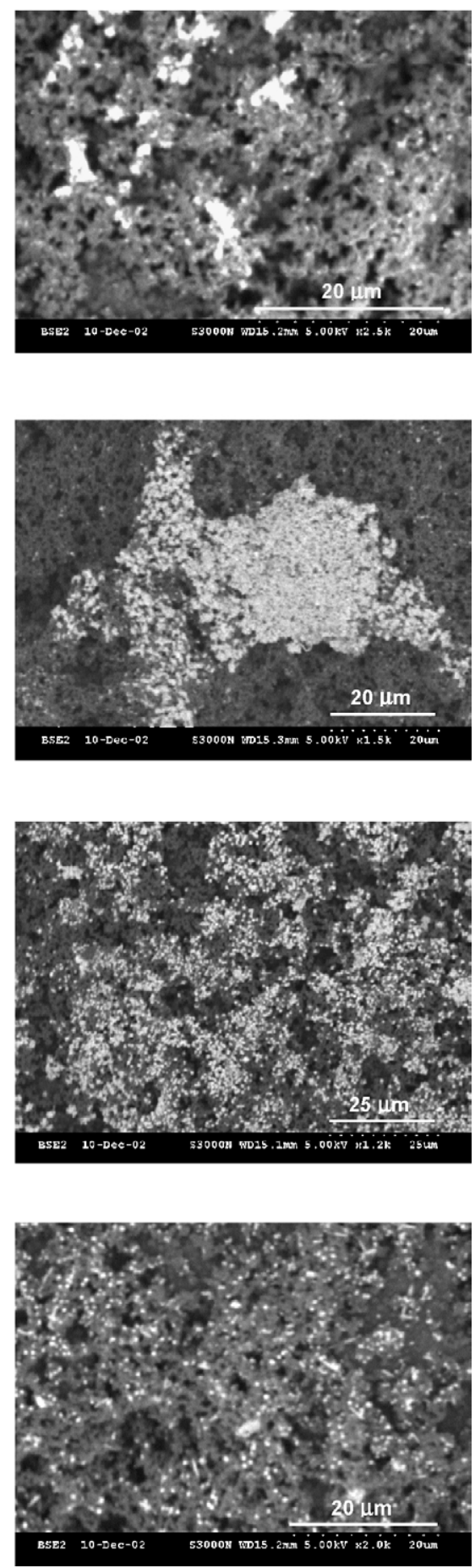

Fig. 5. SEM images obtained in SE and BSE detection modes of varying concentrations of Ab-gold colloids on PANI/PVS-coated electrodes: (A) 10 mg/ml, (B) $5 \mathrm{mg} / \mathrm{ml}$, (C) $1.25 \mathrm{mg} / \mathrm{ml}$, (D) $0.625 \mathrm{mg} / \mathrm{ml}$, (E) $0.5 \mathrm{mg} / \mathrm{ml}$, (F) $0.313 \mathrm{mg} / \mathrm{ml}$, (G) $0.157 \mathrm{mg} / \mathrm{ml}$ and (H) $0.078 \mathrm{mg} / \mathrm{ml}(2500 \times, 2000 \times, 1500 \times$ and $1200 \times \mathrm{magnifications})$. 

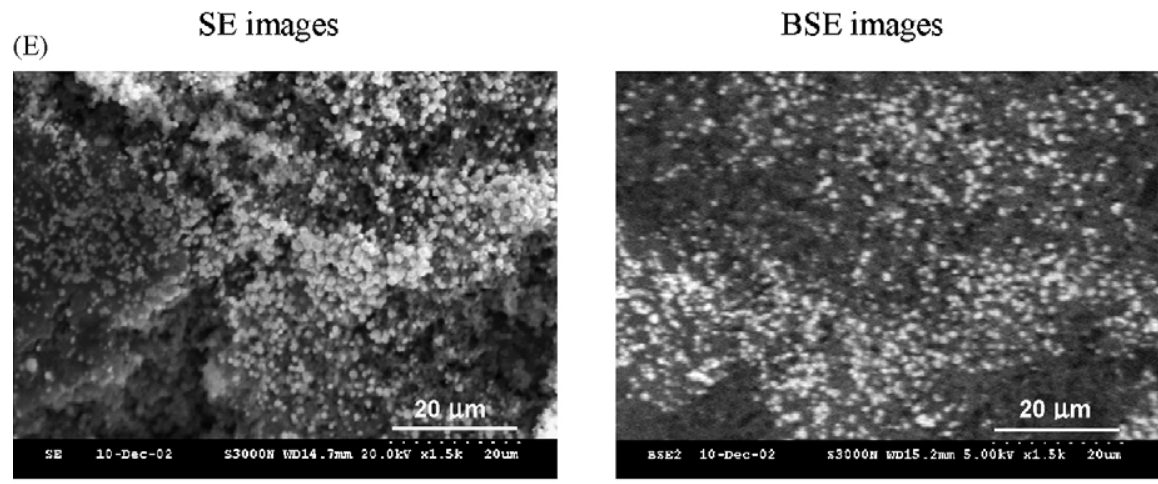

(F)
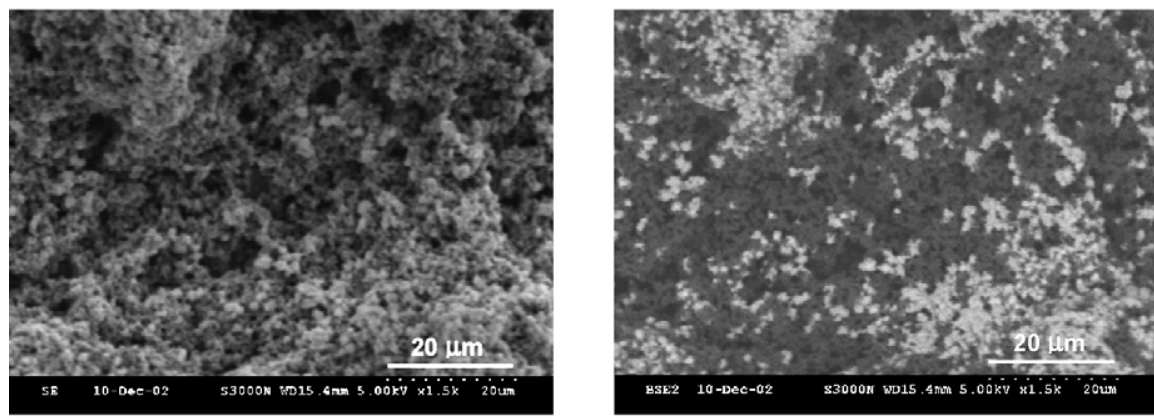

(G)
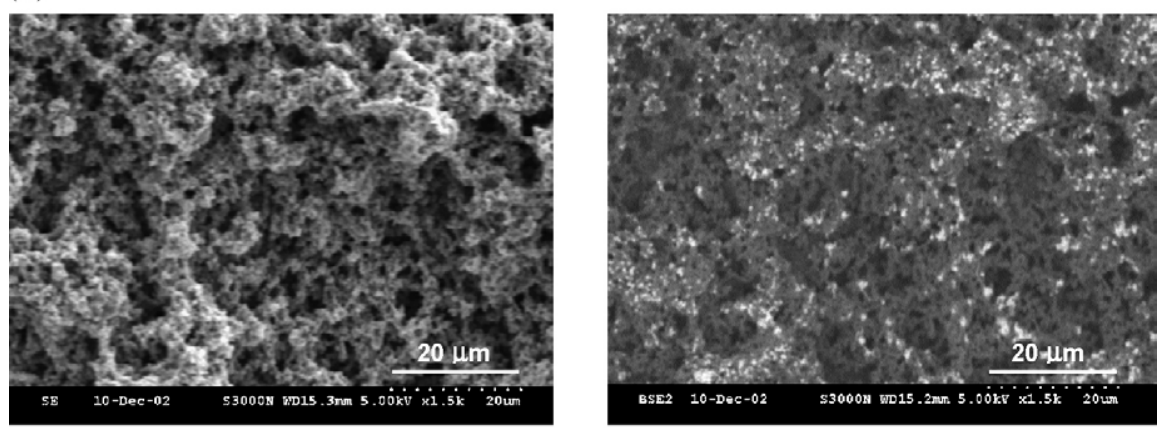

(H)
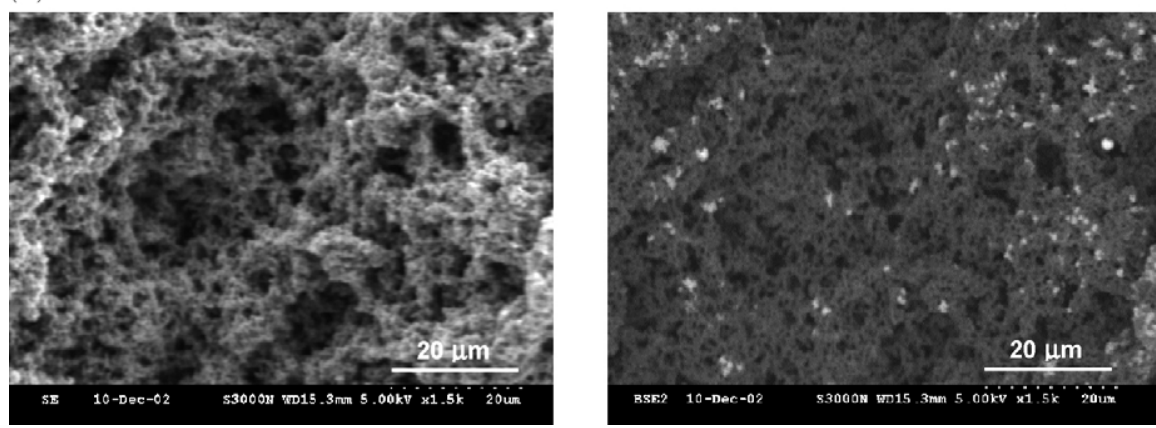

Fig. 5. (Continued).

aggregation or clumping of protein was observed on electrode surfaces. Such clumping was deemed to have been responsible for minimised amperometric signals observed previously at these higher concentrations [10]. This tendency to aggregate had decreased at the $5 \mathrm{mg} / \mathrm{ml}$ concentrations, with a relatively even (though porous) spread of protein remaining on the polymer surface. More uniform surface coverages were also obtained at concentrations of $1.25 \mathrm{mg} / \mathrm{ml}$ (Fig. $5(\mathrm{C})$ ) and $0.625 \mathrm{mg} / \mathrm{ml}$
(Fig. 5(D)), respectively. However, patches of polymer could be observed intermittently between antibody clusters. This trend continued at the lower concentrations of antibody, shown in Fig. 5(E-H), with the sparse distribution of protein reflecting the lower concentrations used. As observed previously, although antibody coverage was low in these cases, the amperometric signals were still larger than for electrodes coated with higher concentrations of antibody [10]. This could be attributed to reduced 
instances of antibody clumping at lower concentrations, resulting in more effective communication between enzyme labels and electrode surfaces.

\section{Conclusions}

Electrochemically polymerised PANI films have been shown to possess a nodular structure on electrode surfaces, with film thicknesses influencing various aspects of sensor responses. Increasing the thickness of polymer films resulted in sensors displaying increased response times as well as background and charging currents. In terms of catalytic current outputs, film thicknesses of $-6.3 \mathrm{~mA}$ for SPE and $-4.1 \mathrm{~mA}$ for GCE produced the maximum outputs. At thicknesses greater than these, catalytic current responses decreased, possibly due to increased cracking observed in SEM images of such films. However, the increased background currents and responses times obtained at these thicknesses negated such films being used for sensing purposes. Films grown to $-2.8 \mathrm{~mA}$ were therefore chosen as optimal for further work, irrespective of the underlying substrate. These produced films of ca. $13.7 \mu \mathrm{m}$ in thickness. The differences in various aspects of amperometric responses obtained with PANI/PVS films grown on SPE and GCE surfaces could be attributed to differences in the morphology of the finished films.

Through the use of gold-labelling techniques and BSE detection using SEM, proteins were observed to become immobilised onto electrode surfaces, with increased levels of protein clumping observed at increased concentrations. Steric hindrance effects at higher protein concentrations may play a part in the hindrance of substrate access to enzymes located closer to electrodes surfaces.

Although electrochemical polymerisation of aniline affords a means to deposit PANI layers of defined thickness onto screenprinted electrode surfaces, the main drawback of this technique with the SPEs developed is that only a single electrode can be coated at any one time. In addition, this process can only be accomplished using electrochemical instrumentation. Consequently, electrochemical polymerisation does not comply with the requirements of mass-production, especially of single-use sensor devices, with authors of the opinion that cyclic voltammetry is not a suitable deposition technique for industrial applications of PANI [28]. A chemical method of polymerisation has also been investigated in our laboratory, to assess its feasibility as a component of an established biosensor system [29]. Such a method would enable a greater number of electrodes to be prepared in situ without the need for instrumental techniques.
Chemical polymerisation of aniline also has the advantage that it may be carried out on a greater number of electrodes simultaneously, using basic laboratory materials.

\section{References}

[1] D.C. Trivedi, in: H.S. Nalwa (Ed.), Handbook of Organic Conductive Molecules and Polymers: Vol. 2. Conductive Polymers: Synthesis and Electrical Properties, John Wiley \& Sons, New York, 1997.

[2] T.W. Lewis, G.G. Wallace, M.R. Smyth, Analyst 124 (1999) 213.

[3] B. Lu, E.I. Iwuoha, M.R. Smyth, R. O'Kennedy, Anal. Chim. Acta 345 (1998) 59.

[4] E.I. Iwuoha, D. Saenz de Villaverde, N.P. Garcia, M.R. Smyth, J.M. Pingarron, Biosens. Bioelectron. 12 (8) (1997) 749.

[5] T.A. Sergeyeva, N.V. Lavrik, S.A. Piletsky, A.E. Rachkov, A.V. El'skaya, Sens. Actuators B 34 (1996) 283.

[6] A.J. Killard, S. Zhang, H. Zhao, R. John, E.I. Iwuoha, M.R. Smyth, Anal. Chim. Acta 400 (1999) 109.

[7] D. Centonze, A. Guerrieri, F. Palmisano, L. Torsi, P.G. Zambonin, Fresenius J. Anal. Chem. 349 (1994) 497.

[8] A.J. Killard, M.R. Smyth, K. Grennan, L. Micheli, G. Palleschi, Biochem. Soc. Trans. 28 (2000) 81.

[9] K. Grennan, A.J. Killard, M.R. Smyth, Electroanalysis 13 (2001) 745.

[10] A.J. Killard, L. Micheli, K. Grennan, M. Franek, V. Kolar, D. Moscone, I. Palchetti, M.R. Smyth, Anal. Chim. Acta 427 (2001) 173.

[11] K. Grennan, G. Strachan, A.J. Porter, A.J. Killard, M.R. Smyth, Anal Chim. Acta 500 (2003) 287.

[12] A. Morrin, A. Guzman, A.J. Killard, J.M. Pingarron, M.R. Smyth, Biosens. Bioelectron. 18 (2003) 715.

[13] E. Naudin, P. Gouérec, D. Bélanger, J. Electroanal. Chem. 459 (1998) 1.

[14] J.C. Michaelson, A.J. McEvoy, M. Gratzel, Synth. Met. 55-57 (1993) 1564.

[15] H. Berney, P. Roseingrave, J. Alderman, W. Lane, J.K. Collins, Sens. Actuators B 44 (1997) 341.

[16] S. Mu, J. Electroanal. Chem. 370 (1994) 135.

[17] H. Xue, S. Mu, J. Electroanal. Chem. 397 (2001) 241.

[18] S. Mu, H. Xue, B. Qian, J. Electroanal. Chem. 304 (1991) 7.

[19] Y. Yang, S. Mu, J. Electroanal. Chem. 415 (1996) 71.

[20] H. Wang, S. Mu, Sens. Actuators B 56 (1-2) (1999) 22.

[21] H. Wang, S. Mu, J. Electroanal. Chem. 436 (1997) 43.

[22] M.E.G. Lyons, C.H. Lyons, C. Fitzgerald, T. Bannon, Analyst 118 (1993) 361.

[23] S. Mu, H. Xue, Sens. Actuators B 31 (1996) 155

[24] R.L. Shepherd, Ph.D. Thesis, University of Wollongong, 2001.

[25] T.W. Lewis, G.G. Wallace, C.Y. Kim, D.Y. Kim, Synth. Met. 84 (1997) 403.

[26] J.I. Reyes De Corcuera, R.P. Cavalieri, J.R. Power, Synth. Met. 142 (2004) 71.

[27] P.N. Bartlett, J.W. Gardner, R.G. Whitaker, Sens. Actuators B A21-A23 (1990) 911.

[28] J.-L. Camalet, J.-C. Lacroix, T. Dung Nguyen, S. Aeiyach, M.C. Pham, J. Petitjean, P.-C. Lacaze, J. Electroanal. Chem. 485 (2000) 13.

[29] K. Grennan, A.J. Killard, M.R. Smyth, Electroanalysis 17 (2005) 1360. 